\title{
TcpC secreting uropathogenic $E$. coli promoted kidney cells to secrete MIP-2 via p38 MAPK pathway
}

\author{
YUJIE HE $^{1,2^{*}}$, JIE FANG $^{1 *}$, CHONG ZHANG $^{1 *}$, JUN PAN $^{3}$, QI JIN ${ }^{1,2}$, YINGZHI YANG $^{1}$, \\ LINYAO WANG $^{1}$, BAOMING WANG ${ }^{1}$, DAYONG ZHANG ${ }^{1}$ and JIANPING PAN ${ }^{1}$
}

\author{
${ }^{1}$ Department of Clinical Medicine, School of Medicine, Zhejiang University City College, Hangzhou, Zhejiang 310015; \\ ${ }^{2}$ Department of Pathogen Biology, Zhejiang University School of Medicine, Hangzhou, Zhejiang $310058 ;{ }^{3}$ Cancer Institute, \\ Second Affiliated Hospital of Zhejiang University School of Medicine, Hangzhou, Zhejiang 310007, P.R. China
}

Received August 25, 2016; Accepted July 6, 2017

DOI: $10.3892 / \mathrm{mmr} .2017 .7021$

\begin{abstract}
Pyelonephritis is an infection of the upper urinary tract with characteristic histological change to neutrophil infiltration in the kidney. The majority of pyelonephritis is caused by uropathogenic Escherichia (E.) coli (UPEC) bearing distinct virulence factors. Toll/interleukin-1 receptor domain-containing protein $\mathrm{C}(\mathrm{TcpC})$ encoded by $E$. coli is an important virulence factor in the majority of strains of UPEC and inhibits macrophage-mediated innate immunity, which serves an essential role in the pathogenesis of pyelonephritis In the present study, it was demonstrated that TcpC induced kidney cells to produce macrophage inflammatory protein-2 (MIP-2; also known as C-X-C motif chemokine 2). MIP-2 concentration in kidney homogenates from TcpC-secreting UPEC CFT073 $\left(\mathrm{TcpC}^{\mathrm{wt}}\right)$ murine pyelonephritis models was significantly higher compared with that in kidney homogenates from $t c p C$ knockout CFT073 $\left(\mathrm{TcpC}^{-1-}\right)$ models. In vitro, $\mathrm{TcpC}^{\mathrm{wt}}$ dose-dependently promoted MIP-2 secretion in HEK-293 cells. The concentration of MIP-2 in culture supernatants of HEK-293 co-cultured with TcpC ${ }^{\mathrm{wt}}$ was profoundly higher compared with that of HEK-293 co-cultured with $\mathrm{TcpC}^{-1-}$. In the presence of anti-TcpC antibody, the enhancement effect
\end{abstract}

Correspondence to: Professor Jianping Pan, Department of Clinical Medicine, School of Medicine, Zhejiang University City College, 51 Huzhou Street, Hangzhou, Zhejiang 310015, P.R. China E-mail: jppan@zucc.edu.cn

*Contributed equally

Abbreviations: UTI, urinary tract infection; UPEC, uropathogenic Escherichia coli; TcpC, toll/interleukin-1 receptor domain-containing protein encoded by E. coli; MIP-2, macrophage inflammatory protein-2; TcpC ${ }^{\mathrm{wt}}$, TcpC-secreting wild-type UPEC CFT073 strain; TcpC ${ }^{-1}$, $t c p C$ knock-out UPEC CFT073 strain; MAPK, mitogen-activated protein kinase; NLRP3, NACHT leucin-rich repeat PYD protein 3

Key words: uropathogenic E. coli, pyelonephritis, TcpC, MIP-2, neutrophil, p38 MAPK of $\mathrm{TcpC}^{\mathrm{wt}}$ on MIP-2 production was completely abrogated, suggesting that the enhanced production of MIP-2 was mediated by secreted TcpC. Furthermore, it was demonstrated that $\mathrm{TcpC}^{-/-}$treatment had no effect on the p38 mitogen activated protein kinase (MAPK) signaling pathway, while $\mathrm{TcpC}^{\mathrm{wt}}$ treatment resulted in the activation of p38 MAPK in HEK-293 cells, as indicated by a simultaneous increase in p38 and phosphorylated-p38. In addition, inhibition of p38 MAPK with SB203580 significantly decreased MIP-2 concentration and neutrophil recruitment activity in the supernatants of HEK-293 cells co-cultured with $\mathrm{TcpC}^{\mathrm{wt}}$. This indicates that TcpC may promote MIP-2 production in kidney cells through the p38 MAPK signaling pathway. Taken together, the data of the present study demonstrated that TcpC can induce MIP-2 production, which may contribute to the characteristic histological change associated with pyelonephritis. This data has provided novel evidence to further clarify the pathogenesis of pyelonephritis and novel directions on the pathogenicity of TcpC-secreting UPEC.

\section{Introduction}

Pyelonephritis, one of the most serious forms of urinary tract infection (UTI), is an infection of the upper urinary tract involving bacterial invasion of the renal parenchyma, and is usually caused by the ascent of bacteria from the bladder to the renal medulla via the ureters $(1,2)$. Up to a quarter of the hospitalizations for UTI involve infection of the kidney or pyelonephritis, causing serious conditions including sepsis and septic shock (3). Neutrophil infiltration is a characteristic pathological change in pyelonephritis. Neutrophils have been implicated in the antibacterial defense of the urinary tract, and neutrophil recruitment to the infected urinary tract is initiated when bacteria stimulate the epithelial cells to secrete chemokines and express chemokine receptors (4). Although neutrophils are essential to host defense, they have also been implicated in the pathology of many inflammatory conditions and tissue injury (5). Neutrophil recruitment is an important early step in controlling tissue infections or injury, and it promotes early and robust inflammation (6).

Since neutrophil recruitment can cause severe tissue damage, understanding neutrophil trafficking mechanisms is 
important to attenuate neutrophil-mediated damage. Several neutrophil chemoattractants have been characterized, of which CXCL2 also known as macrophage inflammatory protein-2 (MIP-2) is especially important (7). MIP-2 is a member of a family of cytokines that play roles in inflammatory, immune, and wound healing responses (8). MIP-2 is required for peripheral neutrophil migration across the epithelium into the urine and can be produced not only by non-immune cells such as epithelial cells and fibroblasts (9), but also by immune cells including dendritic cells (10). Several signaling pathways such as PI3K and NF- $\mathrm{B} / \mathrm{ERK}$ are associated with MIP-2 production during inflammatory condition $(11,12)$. p38 MAPK, one of three distinct families of MAPKs (p42/44 or ERK kinase, JNK kinase, and p38 kinase), is a critical enzyme for cytokine TNF production and is currently targeted for anti-inflammatory therapy (13). p38 MAPK was significantly activated and up-regulated by both acute and chronic cigarette smoke exposure in C57BL/6 mouse model with obstructive pulmonary disease. Inhibition of p38 MAPK signaling pathway profoundly attenuated cigarette smoke induced lung inflammation, which was evidenced by the reduced infiltration of neutrophils and concentration of MIP-2 in the lung after intra-peritoneally administration of p38 MAPK inhibitor (14). These data are in accordance with the earlier discovery or inhibition of p38 MAPK prevents neutrophil chemoattractant production and blocks chemotaxis of neutrophils (15).

Escherichia coli (E. coli) is the most common pathogen for pyelonephritis, and the severity of pyelonephritis caused by $E$. coli is due to the expression of a wide range of virulence factors. Many virulence factors play key roles in the pathogenicity of these $E$. coli strains termed uropathogenic E. coli (UPEC) (16-18). TcpC, a novel virulence factor of extraintestinal pathogenic $E$. coli, inhibits toll-like receptor (TLR) and MyD88-specific signaling, thus impairs the innate immune response, promotes bacterial survival and increases the severity of UTIs in humans and mice (19-21). TcpC is common in the most virulent UPEC strains, it can also directly interact with the NACHT leucin-rich repeat PYD protein 3 (NLRP3) inflammasome and caspase-1, hereby inhibiting the activation of NLRP3 inflammasome and caspase-1, leading to the reduction of IL-1 $\beta$ production (22). However, the influence of TcpC on MIP-2 production by kidney cells remains elucidative. In the present study, we showed that TcpC could promote MIP-2 production and neutrophil recruitment in renal cells via p38 activation, which might contribute to the pathogenesis of pyelonephritis.

\section{Materials and methods}

Mice and reagents. C57BL/6 mice $\left(\mathrm{H}-2^{\mathrm{b}}\right), 8-10$ weeks of age, were purchased from SLC Laboratory Animal Co., Ltd. (Shanghai, China), and were housed in specific pathogen-free conditions. All the animal procedures were performed according to the proper used and care of laboratory animals by the Institutional Committee. The primary antibodies against p38, p-p38 (Thr180/Tyr182), p-JNK1/2, p-ERK1/2, PI3K, $\beta$-actin, and horseradish peroxidase (HRP)-labeled secondary anti-mouse and anti-rabbit antibodies were purchased from Santa Cruz Biotechnology
(Santa Cruz, CA, USA). The p38 MAPK inhibitor SB203580 was purchased from Selleck Chemicals (Houston, TX, USA) and dissolved in dimethyl sulfoxide (DMSO) (10 mM stock solution) and stored at $-20^{\circ} \mathrm{C}$. TcpC expressing uropathogenic $E$. coli strain CFT073 (TcpC ${ }^{\mathrm{wt}}$ ) was kindly provided by Professor Jian-Guo Xu (State Key Laboratory for Infectious Disease Prevention and Control, National Institute for Communicable Disease Control and Prevention, China). The tcp $\mathrm{C}$-knock out CFT073 strain $\left(\mathrm{TcpC}^{-/-}\right)$was constructed by $\lambda$ red homologous recombination as described in our previous published paper (23). Rabbit anti-TcpC polyclonal antibody ( $\mathrm{IgG}$ ) was produced in our laboratory. Rabbit IgG isotype control was purchased from Beyotime Biotechnology (Shanghai, China).

Cell culture. Human embryonic kidney cell line (HEK-293) was purchased from Shanghai Institute of Biochemistry and Cell Biology (Shanghai, China), and the genotypes were authenticated by DNA fingerprinting. HEK-293 was grown in DMEM medium containing $10 \%$ fetal bovine serum (FBS) plus $2 \mathrm{mM}$ glutamine and 50 units $/ \mathrm{ml}$ penicillin in a humidified atmosphere of $5 \% \mathrm{CO}_{2}$ at $37^{\circ} \mathrm{C}$.

Transwell co-culture. Co-culture of HEK-293 cells with wild-type E. coli CFT073 (TcpC ${ }^{\mathrm{wt}}$ ) and $\mathrm{TcpC}^{-/}$was performed in transwell system (Corning, NY, USA) as previously described (24). Briefly, $1 \mathrm{ml}$ HEK-293 cell suspension $\left(5.0 \times 10^{5}\right.$ cells) was added to the lower compartment of the transwell, and $0.2 \mathrm{ml}$ containing different numbers of $\mathrm{TcpC}^{\mathrm{wt}}$ or $\mathrm{TcpC}^{-/-}$was added to the upper compartment of the transwell $(0.4 \mu \mathrm{m}$ transwell filters). To conform the influence of $\mathrm{TcpC}^{\mathrm{wt}}$ on the MIP-2 production was caused by the TcpC secreted by $\mathrm{TcpC}^{\mathrm{wt}}, 5.0 \times 10^{5} \mathrm{HEK}-293$ cells were separately co-cultured in transwell system with or without $\mathrm{TcpC}^{\mathrm{wt}}$ at multiplicity of infection $(\mathrm{MOI})=1$ in the presence or absence of $10 \mu \mathrm{g} / \mathrm{ml}$ of rabbit anti-TcpC polyclonal antibodies or rabbit IgG isotype control for $15 \mathrm{~h}$. To examine the influence of $\mathrm{p} 38$ MAPK inhibitor on the production of MIP-2, HEK-293 cells were pretreated with SB203580 $(1.25 \mu \mathrm{M})$ or solvent DMSO for $1 \mathrm{~h}$ and then co-cultured with $\mathrm{TcpC}^{\mathrm{wt}}$ or $\mathrm{TcpC}^{-/-}$for $15 \mathrm{~h}$. Culture of HEK-293 cells without bacteria served as the blank control.

Mouse pyelonephritis model. $\mathrm{TcpC}^{\mathrm{wt}}$ and $\mathrm{TcpC}^{-/-}$were grown in LB medium and harvested by centrifugation at 4,000 x g for $5 \mathrm{~min}$ and resuspended in $1 \mathrm{ml}$ of $\mathrm{LB}$ medium to a final concentration of $1 \times 10^{11} \mathrm{CFU} / \mathrm{ml}$. Female C57BL/6 mice of 8 to 10 weeks of age were anesthetized with Avertin [40 mg of 2,2,2-tribromoethanol (Sigma-Aldrich; Merck KGaA, Darmstadt, Germany) dissolved in $1 \mathrm{ml}$ of tertamyl alcohol $(0.01 \mathrm{ml} / \mathrm{g}$ body weight intraperitoneally)] and infected by transurethral instillation of $0.1 \mathrm{ml}$ of the bacterial suspension or LB medium using a flexible polyethylene catheter. The infected mice were sacrificed 3 days later and the kidneys were obtained for histological analysis and detection of MIP-2.

Histological analysis. Paraformaldehyde-fixed and paraffinembedded kidneys were sectioned at $4 \mu \mathrm{m}$ and stained with hematoxylin and eosin using the standard method. These sections were observed with a light microscopy to determine 
the histological changes in kidneys from the control, TcpC $\mathrm{C}^{\mathrm{wt}}$ and $\mathrm{TcpC}^{--}$-treated mice.

Detection of MIP-2 in the culture supernatants and in the homogenates of kidney. Concentrations of MIP-2 in the culture supernatants and kidney homogenates were determined by using commercially available ELISA kits (R\&D Systems, Minneapolis, MN, USA and Abcam, Cambridge, MA, USA, respectively) according to the manufacturer's instructions. To make homogenates of kidney, a $200 \mathrm{mg}$ portion of the left kidney of the mouse from different groups was homogenized in $1 \mathrm{ml} \mathrm{PBS}$. After centrifugation at 8,000 x g for $10 \mathrm{~min}$ at $4^{\circ} \mathrm{C}$, the supernatant was collected and stored at $-20^{\circ} \mathrm{C}$ for measurement of MIP-2.

Cell lysate preparation and western blot analysis. Proteins were extracted with lysis buffer $(50 \mathrm{mM}$ Tris- $\mathrm{HCl}, 150 \mathrm{mM}$ $\mathrm{NaCl}, 1 \mathrm{mM}$ EDTA, $0.1 \%$ SDS, $0.5 \%$ deoxycholic acid, $0.02 \%$ sodium azide, $1 \% \mathrm{NP}-40,2.0 \mu \mathrm{g} / \mathrm{ml}$ aprotinin, $1 \mathrm{mM}$ phenylmethylsulfonylfluoride). The lysates were centrifuged at $10,000 \mathrm{x} \mathrm{g}$ for $30 \mathrm{~min}$ at $4^{\circ} \mathrm{C}$, the supernatants were transferred to a new tube, and the protein concentration was determined. Protein samples were fractionated on 8 to $15 \%$ Tris-glycine gels, followed by proteins transfer onto a PVDF membrane (Millipore, Bedford, MA, USA). The membranes were blocked with 5\% non-fat dry milk and then probed with primary antibodies (dilution range, 1:500-1:1,000), followed by HRP-labeled secondary antibodies at a 1:5,000 dilution. Antibody binding was visualized with a chemiluminescent substrate and visualized on autoradiography film.

Neutrophil isolation and chemotaxis assay. Neutrophils were isolated as described (25). Briefly, venous blood of healthy volunteers was collected on anticoagulant $3.8 \%$ sodium citrate solution (blood to sodium citrate is 9:1 in volume), centrifuged $500 \mathrm{x}$ g for $15 \mathrm{~min}$ and the resulting platelet-rich plasma was discarded. The leucocyte-rich upper layer was then aspirated, placed on top of a Percoll (Sigma-Aldrich) step gradient (60 and 75\% Percoll in PBS) and centrifuged at 2,000 rpm for $15 \mathrm{~min}$. The enriched neutrophil population was recovered at the interface between 60 and $75 \%$ Percoll. The purified neutrophils were resuspended in RPMI 1640 containing 10\% FBS medium and used freshly for migration assays. Neutrophil migration was carried out in a transwell system. Briefly, cell culture inserts ( $8 \mu \mathrm{m}$ pore size) were used to form dual compartments (upper and bottom chamber) in a 24-well culture plate. Freshly purified human peripheral blood neutrophils were loaded into the upper chamber (cell culture insert) and their migration was initiated by the addition of the MIP-2 containing culture supernatants to the bottom chamber in a 24 -well plate. Neutrophil migration was carried out for $12 \mathrm{~h}$ at $37^{\circ} \mathrm{C}$ and $5 \% \mathrm{CO}_{2}$. The migrated neutrophils were collected from the bottom chambers and counted with a hemacytometer. Neutrophil migration to the supernatants of HEK-293 cells treated with $\mathrm{TcpC}^{\mathrm{wt}}$ was set as $100 \%$.

Statistical analysis. All the experiments were performed at least three times, and results were expressed as mean \pm SD. Two-tailed Student's t-test was used to determine the significance of the differences between the experimental conditions. Differences were considered significant at $\mathrm{P}<0.05$.

\section{Results}

TcpC plays an important role in the pathogenesis of pyelonephritis. Since neutrophils are involved in the pathology of various inflammatory conditions (25), and neutrophil infiltration is a characteristic pathological change of acute pyelonephritis $(10,19)$, we examined the histological changes of kidneys from mice models with pyelonephritis. As shown in Fig. 1, in accordance with previous reports $(10,19)$, few neutrophils were seen in kidneys of C57BL/6 mice infected by $\mathrm{TcpC}^{-/-}$, but large numbers of neutrophils were infiltrated in kidneys from mice infected by $\mathrm{TcpC}^{\mathrm{wt}}$, indicating $\mathrm{TcpC}$ plays an important role in the pathogenesis of pyelonephritis.

TcpC promoted MIP-2 production in vivo and in vitro. Because MIP-2 exhibits potent neutrophil chemotactic activity and plays a major role in mediating the neutrophilic inflammation (9), we detected the levels of MIP-2 in kidney homogenates of pyelonephritis mouse models caused by $\mathrm{TcpC}^{\mathrm{wt}}$ or $\mathrm{TcpC}^{--}$. A marked MIP-2 in vivo response to infection of $\mathrm{TcpC}^{\mathrm{wt}}$ but a weak response to infection of $\mathrm{TcpC}^{-/-}$in the C57BL/6 mice can be observed (Fig. 2). Concentration of MIP-2 in kidney homogenates of $\mathrm{TcpC}^{\mathrm{wt}}$-caused pyelonephritis was significantly higher than that in kidney homogenates of $\mathrm{TcpC}^{-/}$-caused pyelonephritis $(\mathrm{P}<0.01)$. In order to examine the in vitro influence of TcpC on the production of MIP-2 by kidney cells, HEK-293 cells were separately co-cultured with $\mathrm{TcpC}^{\mathrm{wt}}$ or $\mathrm{TcpC}^{-/}$at different MOI in transwell for $15 \mathrm{~h}$ and concentrations of MIP-2 in supernatants were detected. As shown in Fig. 3A, TcpC dose-dependently promoted MIP-2 production in HEK-293 cells, concentration of MIP-2 in $\mathrm{TcpC}^{\mathrm{wt}}$ group was profoundly higher than that in the $\mathrm{TcpC}^{-1-}$ group $(\mathrm{P}<0.01)$. To confirm this enhanced production of MIP-2 in $\mathrm{TcpC}^{\mathrm{wt}}$-treated HEK-293 cells was really caused by TcpC, we, at first, analyzed TcpC in the culture supernatants and in the cells of the co-cultured system by western blot analysis. As demonstrated in Fig. 3B, TcpC was found only in both the supernatants and in the cells of the $\mathrm{TcpC}^{\mathrm{wt}}$ group, while no TcpC was detected in the groups of control and $\mathrm{TcpC}^{-1}$. Furthermore, the quantity of TcpC in the group of $\mathrm{TcpC}^{\mathrm{wt}}$ was increased along with the increase of MOI. Then, we observed the influence of TcpC neutralization on MIP-2 production by HEK-293 cells co-cultured with $\mathrm{TcpC}^{\mathrm{wt}}$ (Fig. 4). In the presence of $10 \mu \mathrm{g} / \mathrm{ml}$ rabbit anti-TcpC polyclonal antibodies, the $\mathrm{TcpC}^{\mathrm{wt}}$ induced MIP-2 production in HEK-293 was almost completely abrogated, while the rabbit IgG isotype control had no effect on $\mathrm{TcpC}^{\mathrm{wt}}$-induced MIP-2 production, suggesting that $\mathrm{TcpC}$ was the crucial factor which caused the difference in MIP-2 production between the $\mathrm{TcpC}^{\mathrm{wt}}$ and $\mathrm{TcpC}^{-/-}$groups. These results indicated that TcpC secreted by $\mathrm{TcpC}{ }^{\mathrm{wt}}$ promoted kidney cells to produce MIP-2 both in vitro and in vivo.

TcpC activated p38 MAPK pathway in HEK-293 cells. To confirm the signal transduction pathway of TcpC induced production of MIP-2 in HEK-293 cells, we detected PI3K and MAPK signaling pathways in $\mathrm{TcpC}^{\mathrm{wt}}$ or $\mathrm{TcpC}^{-/}$-treated HEK-293 cells. As shown in Fig. 5A, TcpC ${ }^{-1-}$ treatment had no 


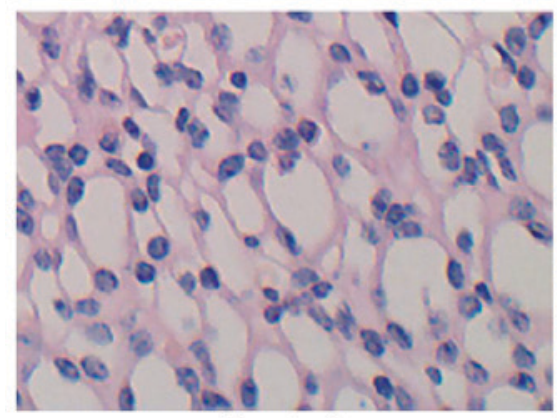

Control

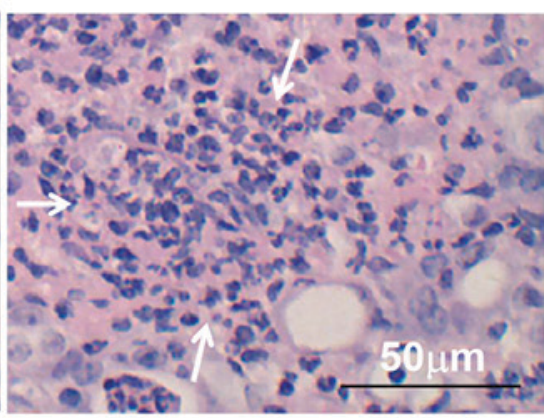

$\mathrm{TcpCwt}$

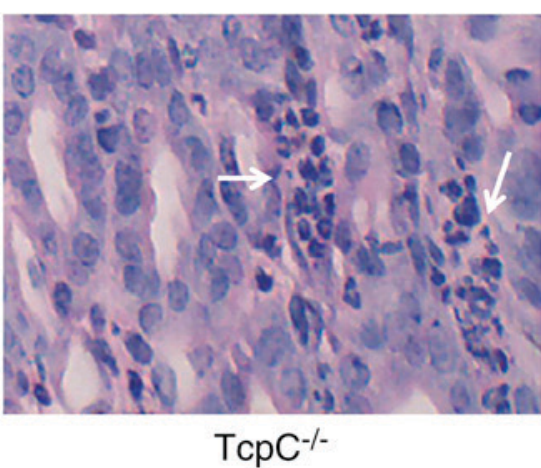

$\mathrm{TcpC}^{-/-}$

Figure 1. Histological examinations of kidneys from pyelonephritis mouse models. Female C57BL/6 mice of 8 to 10 weeks of age were anesthetized with Avertin. Subsequently, $1 \times 10^{10} \mathrm{CFU} \mathrm{TcpC}{ }^{\mathrm{wt}}$ or $\mathrm{TcpC}^{-/-}$suspension $(0.1 \mathrm{ml})$ were transurethral infused into the bladder of the anesthetized mice through a flexible polyethylene catheter. The mice were sacrificed 3 days later and the kidneys were obtained and fixed in paraformaldehyde. Paraffin-embedded kidneys were sectioned at $4 \mu \mathrm{m}$ and stained with hematoxylin and eosin. Representative images were captured using an Olympus CKX41 microscope (x400). Arrows indicated the fields of neutrophil infiltration. TcpC, Toll/interleukin-1 receptor domain-containing protein encoded by E. coli; TcpC ${ }^{\text {wt }}$, TcpC-secreting wild-type UPEC CFT073 strain; TcpC ${ }^{--}$, tcpC knock-out UPEC CFT073 strain

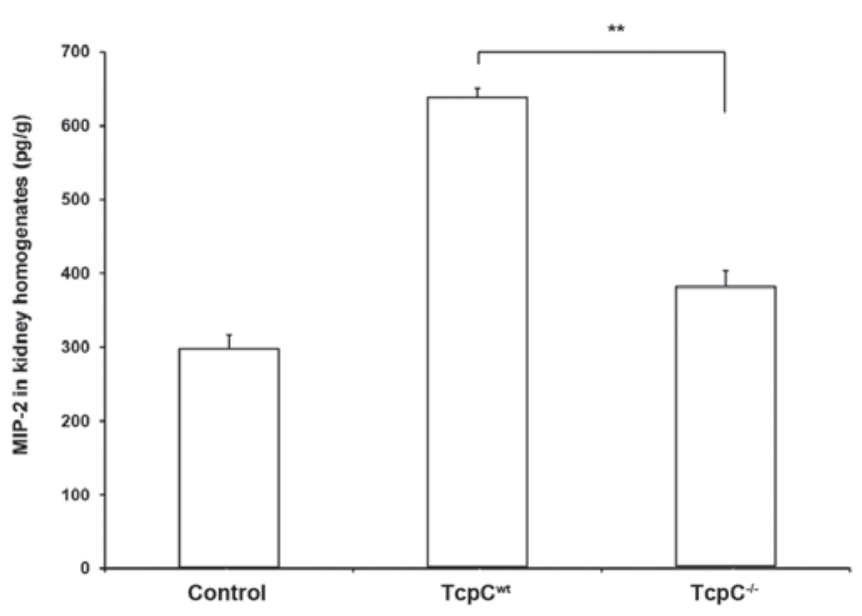

Figure 2. MIP-2 concentrations of kidney homogenates in pyelonephritis mouse models. The mouse pyelonephritis model was performed as described in Materials and methods. The levels of MIP-2 in kidney homogenates were measured by ELISA. ${ }^{* *} \mathrm{P}<0.01$. MIP-2, macrophage inflammatory protein-2; TcpC, Toll/interleukin-1 receptor domain-containing protein encoded by E. coli; $\mathrm{TcpC}^{\mathrm{wt}}$, TcpC-secreting wild-type UPEC CFT073 strain; $\mathrm{TcpC}^{-1 /}$, tcpC knock-out UPEC CFT073 strain.

effect on $\mathrm{p} 38$ MAPK pathway, while TcpC ${ }^{\text {wt }}$ treatment resulted in the activation of p38 MAPK in HEK-293 cells, as indicated by a simultaneous increase of $\mathrm{p} 38$ and p-p38 (Thr180/Tyr182). No significant changes of p-JNK1/2, p-ERK1/2 and PI3K proteins in $\mathrm{TcpC}^{\mathrm{wt}}$ or $\mathrm{TcpC}^{-/-}$-treated HEK-293 cells were observed (Fig. 5A), indicating that JNK, ERK and PI3K signaling pathways might not be involved in TcpC induced MIP-2 production by HEK-293 cells.

Inhibition of p38 MAPK blocked TcpC-induced MIP-2 production in HEK-293 cells. To further analyze whether phosphorylation and activation of p38 MAPK was required for TcpC-mediated MIP-2 production, we tested the effect of p38 MAPK inhibitor SB203580 on the secretion of MIP-2 induced by TcpC in HEK-293 cells. The secretion of MIP-2 induced by $\mathrm{TcpC}^{\mathrm{wt}}$ was consistently inhibited $(\mathrm{P}<0.01)$ by $\sim 25 \%$, when HEK-293 cells were pre-incubated with p38 MAPK inhibitor SB203580 (Fig. 5B). Unsurprisingly, the difference in MIP-2 production between the groups of Control and $\mathrm{TcpC}^{-/-}$with p38 MAPK inhibitor SB203580 can be seen, suggesting that factors other than TcpC and p38 might also be involved in MIP-2 production. In accordance with the effect of SB203580 on MIP-2 production by TcpC ${ }^{\text {wt }}$-treated HEK-293 cells, neutrophil chemotaxis mirrored the same trend. Neutrophil chemotaxis to MIP-2 containing supernatants of TcpC ${ }^{\text {wt }}$-treated HEK-293 cells was blocked by $\sim 45 \%$ if the HEK-293 cells were pretreated with the p38 MAPK inhibitor SB203580 (Fig. 5C). These data suggested that in vitro inhibition of p38 MAPK could abrogate MIP-2 production induced by TcpC ${ }^{\mathrm{wt}}$ in HEK-293 cells.

\section{Discussion}

Pyelonephritis is the most severe form of UTI (26), and it is mainly caused by infection of UPEC (16). With the increasing frequency of antibiotic resistance among uropathogens (27), further understanding of the pathogenesis of pyelonephritis is beneficial to the treatment of the disease.

The characteristic pathological change of bacterial pyelonephritis is neutrophil infiltration $(10,19)$. Neutrophils are the double-edged sword in many inflammatory diseases (28). On one hand, neutrophils are the essential effector cells of the innate immune response, forming the first line of defense against bacterial and fungal pathogens (29). Pharmacological or genetic inhibition of neutrophil migration/activation has been shown to drastically impair the antibacterial defense, resulting in poor bacterial clearance and drastic tissue pathology (30). On the other hand, neutrophils are attracted in large numbers to infection site and cause tissue damage during inflammatory responses (31). It was demonstrated that neutrophils contributed significantly to tissue damage in acute disease processes, such as acute lung injury and spinal cord injuries, as well as in chronic disease processes, such as rheumatoid arthritis and asthma (32). TcpC is clinically relevant as a virulence factor in some strains of UPEC that cause severe pyelonephritis (19). In our study, we have observed that large numbers of neutrophils were infiltrated in kidneys from mouse pyelonephritis models caused by $\mathrm{TcpC}{ }^{\mathrm{wt}}$, but not by $\mathrm{TcpC}^{-1-}$. These results demonstrated that TcpC secreted by 


\section{A}
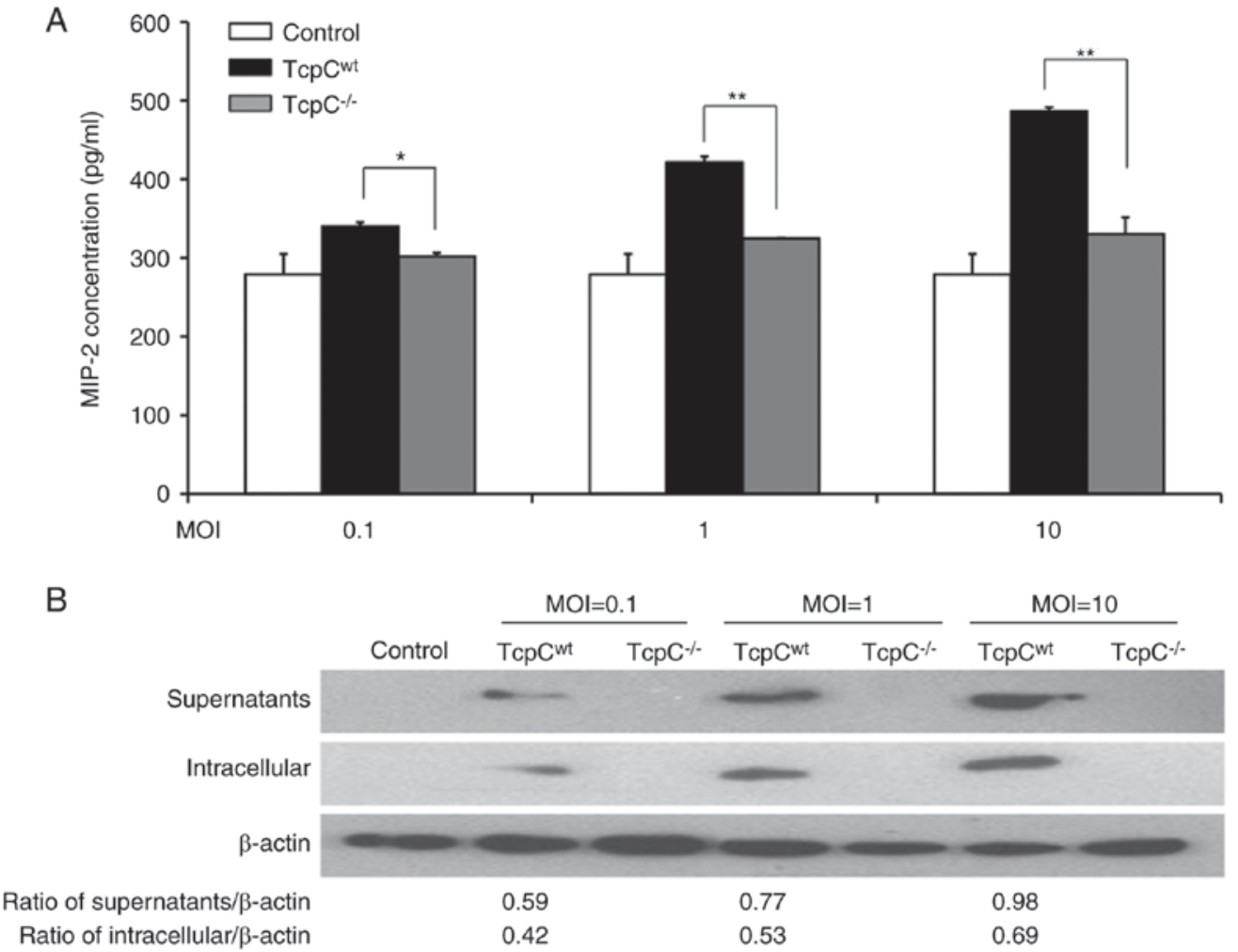

Figure 3. TcpC ${ }^{\mathrm{wt}}$-induced MIP-2 production in HEK-293 cells in a dose-dependent manner. (A) A total of 5.0x105 HEK-293 cells were co-cultured with or without $\mathrm{TcpC}^{\mathrm{wt}}$ and $\mathrm{TcpC}^{-/}$at different MOI in transwell for $15 \mathrm{~h}$. MIP-2 concentrations in the supernatants were measured by ELISA (B) For analyses of supernatant and intracellular TcpC in the co-culture system, the supernatants were concentrated for 5 -fold by ultrafilter. TcpC in the concentrated supernatants and in the cells were detected by western blot analysis, and semi-quantitative densitometric analyses were also performed. ${ }^{*} \mathrm{P}<0.05,{ }^{* *} \mathrm{P}<0.01$. TcpC, Toll/interleukin-1 receptor domain-containing protein encoded by E. coli; TcpC ${ }^{\mathrm{wt}}$, TcpC-secreting wild-type UPEC CFT073 strain; TcpC ${ }^{-/-}$, tcpC knock-out UPEC CFT073 strain; MIP-2, macrophage inflammatory protein-2; MOI, multiplicity of infection.

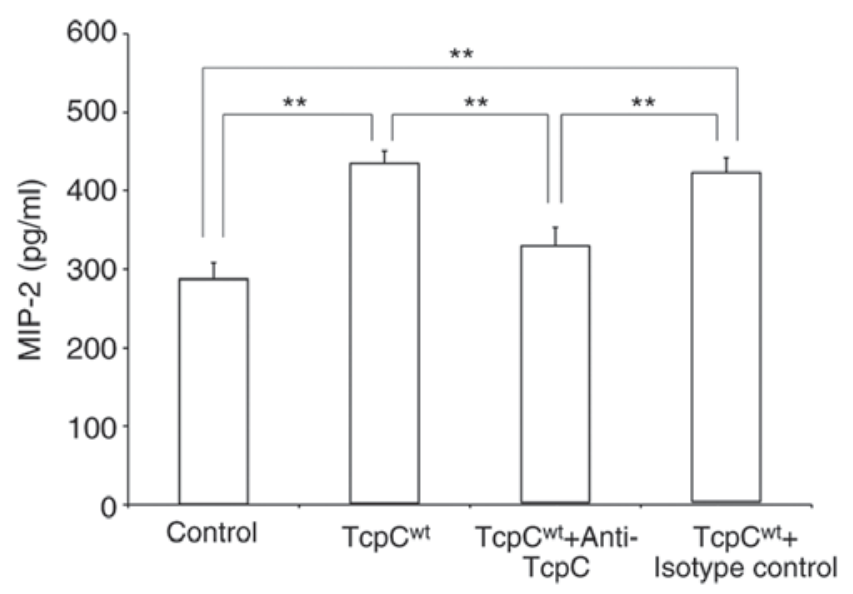

Figure 4. Rabbit anti-TcpC antibody abrogated TcpC ${ }^{\mathrm{wt}}$-induced MIP-2 production in HEK-293 cells. A total of 5.0x10 HEK-293 cells were co-cultured, in transwell, for $15 \mathrm{~h}$ with or without $\mathrm{TcpC}^{\mathrm{wt}}$ at $\mathrm{MOI}=1$ in the presence or absence of $10 \mu \mathrm{g} / \mathrm{ml}$ rabbit anti-TcpC polyclonal antibodies or rabbit $\operatorname{IgG}$ isotype control. Culture supernatants were harvested and MIP-2 concentrations were measured by ELISA. ${ }^{* *} \mathrm{P}<0.01$. TcpC, Toll/interleukin-1 receptor domain-containing protein encoded by E. coli; $\mathrm{TcpC}^{\mathrm{wt}}$, TcpC-secreting wild-type UPEC CFT073 strain; MIP-2, macrophage inflammatory protein-2; MOI, multiplicity of infection.

E. coli facilitated neutrophil recruitment and inflammatory response, which might be one of the mechanisms by which $\mathrm{TcpC}$ contribute to the kidney injury and pathogenesis of pyelonephritis.
Because MIP-2 is one of the most important chemokines that contribute significantly to the influx of neutrophils and their activation $(33,34)$, we, at first, detected MIP-2 concentrations in kidney homogenates of mouse models with pyelonephritis. In accordance with histological examinations that showed large numbers of neutrophils infiltration in the group of $\mathrm{TcpC}^{\mathrm{wt}}$, we demonstrated that $\mathrm{TcpC}^{\mathrm{wt}}$ induced greater MIP-2 response than $\operatorname{did} \mathrm{TcpC}^{-/-}$in the kidneys, indicating that the TcpC producing E. coli might induce, at least in part, neutrophil recruitment via modulation of MIP-2. MIP-2, like many other chemokines, can be produced by a variety of cell types, including macrophages, epithelial cells, and fibroblasts (35) as well as kidney DCs (10). MIP-2 production was triggered by infection, and kidney epitheliums and DCs are the main source of MIP-2 in UTI models $(10,36)$. Using a transwell separate co-culture system, we showed that $\mathrm{TcpC}^{\mathrm{wt}}$ dose-dependently increased MIP-2 production and the concentration of MIP-2 in the group of TcpC ${ }^{\text {wt }}$-treated HEK293 cells was profoundly higher than that in the $\mathrm{TcpC}^{-/-}$-treated group, which was also supported by our western blot analyses of TcpC both in the culture supernatants and in the cells of the co-culture system that showed $\mathrm{TcpC}$ was only detected in the $\mathrm{TcpC}^{\mathrm{wt}}$ groups and the amount of TcpC increased along with the increase of MOI. Furthermore, polyclonal antibodies to TcpC could abrogate the TcpC ${ }^{\mathrm{wt}}$ induced production of MIP-2 in HEK293 cells, confirming that this difference in MIP-2 production between the $\mathrm{TcpC}^{\mathrm{wt}}$-treated HEK293 cells and $\mathrm{TcpC}^{-/-}$-treated group 
A

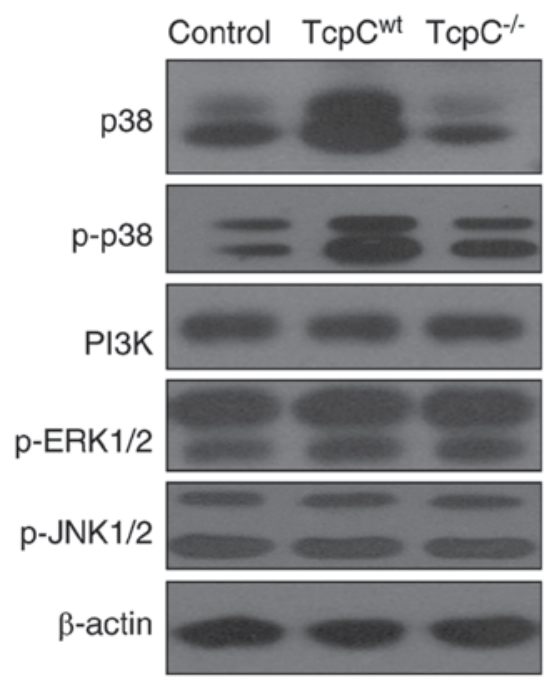

B

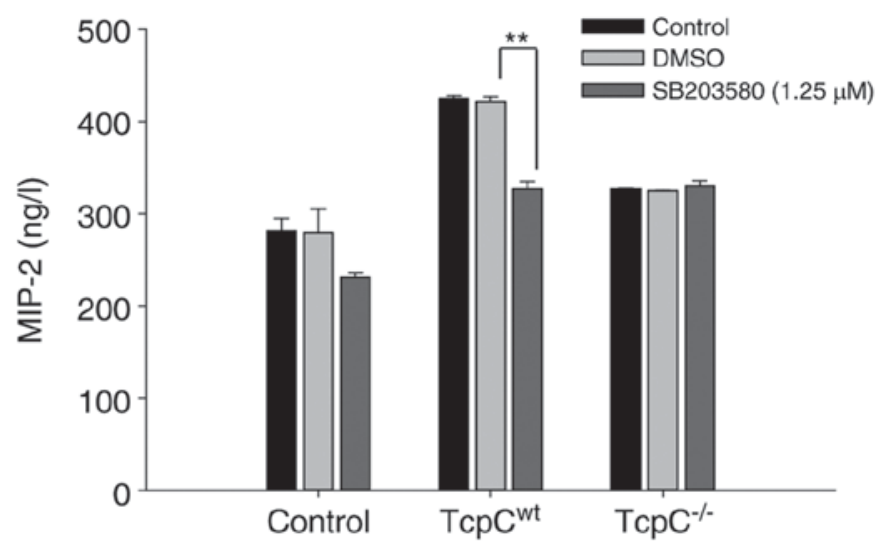

C

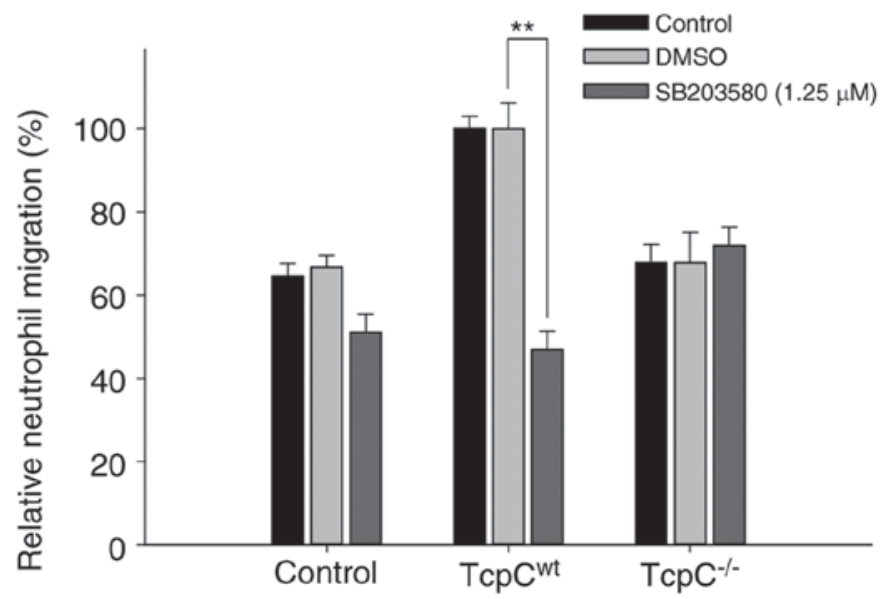

Figure 5. TcpC induced MIP-2 production via p38 signaling pathway in HEK-293 cells. (A) Western blot analyses of p38, p-p38, p-ERK1/2, p-JNK1/2 MAPK and PI3K in HEK293 cells co-cultured with or without $\mathrm{TcpC}^{\mathrm{wt}}$ and $\mathrm{TcpC}^{-/}(\mathrm{MOI}=1)$ for $15 \mathrm{~h}$. (B) Effects of p38 MAPK inhibitor on MIP-2 production in $\mathrm{TcpC}^{\mathrm{wt}}$-or TcpC ${ }^{-/}$-treated and non-treated HEK-293 cells. HEK-293 cells were pre-treated with p38 MAPK inhibitor SB203580 $(1.25 \mu \mathrm{M})$ for $1 \mathrm{~h}$ and then co-cultured with $\mathrm{TcpC}^{\mathrm{wt}}$ or $\mathrm{TcpC}^{-/}$at $\mathrm{MOI}=1$ for $15 \mathrm{~h}$ in transwell system. The concentrations of MIP-2 in the supernatants were determined by ELISA. (C) Neutrophil migration to the MIP-2 containing supernatants of $\mathrm{TcpC}^{\mathrm{wt}}$ or $\mathrm{TcpC}^{-/-}$co-cultured HEK293 cells that were pre-treated with or without p38 MAPK inhibitor SB202580. ${ }^{* *} \mathrm{P}<0.01$. TcpC, Toll/interleukin-1 receptor domain-containing protein encoded by E. coli; TcpC ${ }^{\mathrm{wt}}$, TcpC-secreting wild-type UPEC CFT073 strain; TcpC ${ }^{-/}$, tcpC knock-out UPEC CFT073 strain; MIP-2, macrophage inflammatory protein-2; MOI, multiplicity of infection.

was really caused by TcpC secreted from the wild-type CFT073. Thus, our data showed that UPEC-derived TcpC could induce MIP-2 production both in vitro and in vivo.

Then, we examined which signaling pathway was involved in MIP-2 production induced by TcpC in HEK-293 cells. The MAPK family, including ERK1/2, p38 MAPK, and JNK, has been shown to play key roles in mediating signals triggered by cytokines, growth factors, stress and phagocytosis, and is involved in various cellular functions (37,38). PI3K signaling pathway has been identified as playing central roles in neutrophil chemotaxis and MIP-2 production $(39,40)$. To determine the signaling pathway involved in TcpC-induced MIP-2 production, we examined MAPK and PI3K activation in HEK-293 cells treated by TcpC ${ }^{\mathrm{wt}}$ and $\mathrm{TcpC}^{-/-}$. Changes in JNK, ERK and PI3K family proteins in $\mathrm{TcpC}^{\mathrm{wt}}$ or $\mathrm{TcpC}^{-/-}$-treated HEK-293 cells were detected by western blot analysis, but no activation of ERK1/2, JNK1/2 and PI3K pathway was observed. Interestingly, our data showed that $\mathrm{TcpC}^{\mathrm{wt}}$ treatment resulted in the activation of p38 MAPK in HEK-293 cells, as indicated by a simultaneous increase of p38 and p-p38 (Thr180/Tyr182), while $\mathrm{TcpC}^{-/-}$treatment had no effect on p38 MAPK pathway. Furthermore, inhibition of p38 MAPK by SB203580 could block TcpC induced MIP-2 production in
HEK-293 cells, which was further demonstrated by neutrophil migration assays. Therefore, our data suggested that p38 MAPK was involved in TcpC-induced MIP-2 production by HEK-293 cells.

In conclusion, we presented evidence showing that $E$. coli CFT073 derived TcpC could induce, through p38 MAPK signaling pathway, MIP-2 production by kidney cells both in vitro and in vivo, which might contribute to the generation of characteristic pathological changes, or neutrophil infiltration in the kidneys of pyelonephritis. Our data provided not only novel evidence to further clarify the role of TcpC in the pathogenesis of pyelonephritis, but also further evidence to clarify the pathogenicity of UPEC.

\section{Acknowledgements}

The authors gratefully acknowledge financial support from grants of National Natural Science Foundation of China (81302806, 81671613), Scientific Research Foundation of Zhejiang Health Bureau (2013KYA149), Science and Technology Development Program of Hangzhou (20140633B39, 20150633B44) and Innovation Project for High Level Overseas Returnees in Hangzhou. 


\section{References}

1. Pinson AG, Philbrick JT, Lindbeck GH and Schorling JB: Oral antibiotic therapy for acute pyelonephritis: A methodologic review of the literature. J Gen Intern Med 7: 544-553, 1992.

2. Tambo M,Okegawa T, Shishido T, Higashihara E and Nutahara K: Predictors of septic shock in obstructive acute pyelonephritis. World J Urol 32: 803-811, 2014.

3. Foxman B: Epidemiology of urinary tract infections: Incidence, morbidity, and economic costs. Dis Mon 49: 53-70, 2003.

4. Haraoka M, Hang L, Frendéus B, Godaly G, Burdick M, Strieter R and Svanborg C: Neutrophil recruitment and resistance to urinary tract infection. J Infect Dis 180: 1220-1229, 1999.

5. Bhansali RS, Yeltiwar RK and Bhat KG: Assessment of peripheral neutrophil functions in patients with localized aggressive periodontitis in the Indian population. J Indian Soc Periodontol 17: 731-736, 2013.

6. Hang L, Frendeus B, Godaly G and Svanborg C: Interleukin-8 receptor knockout mice have subepithelial neutrophil entrapment and renal scarring following acute pyelonephritis. J Infect Dis 182: $1738-1748,2000$

7. Montecucco F, Lenglet S, Braunersreuther V, Godaly G, Burdick M, Strieter R and Svanborg C: Single administration of the CXC chemokine-binding protein Evasin-3 during ischemia prevents myocardial reperfusion injury in mice. Arterioscler Thromb Vasc Biol 30: 1371-1377, 2010.

8. Driscoll KE, Hassenbein DG, Howard BW, Isfort RJ, Cody D, Tindal MH, Suchanek M and Carter JM: Cloning, expression, and functional characterization of rat MIP-2: A neutrophil chemoattractant and epithelial cell mitogen. J Leukoc Biol 58: 359-364, 1995.

9. Driscoll KE: TNFalpha and MIP-2: Role in particle-induced inflammation and regulation by oxidative stress. Toxicol Lett 112-113: 177-183, 2000.

10. Tittel AP, Heuser C, Ohliger C, Knolle PA, Engel DR and Kurts C: Kidney dendritic cells induce innate immunity against bacterial pyelonephritis. J Am Soc Nephrol 22: 1435-1441, 2011.

11. Huang YY, Xia MZ, Wang H, Liu XJ, Hu YF, Chen YH, Zhang C and Xu DX: Cadmium selectively induces MIP-2 and COX-2 through PTEN-mediated Akt activation in RAW264.7 cells. Toxicol Sci 138: 310-321, 2014.

12. Tateno N, Matsumoto N, Motowaki T, Suzuki K and Aratani Y: Myeloperoxidase deficiency induces MIP-2 production via ERK activation in zymosan-stimulated mouse neutrophils. Free Radic Res 47: 376-385, 2013.

13. Janssens S and Beyaert R: Functional diversity and regulation of different interleukin-1 receptor-associated kinase (IRAK) family members. Mol Cell 11: 293-302, 2003.

14. Marumo S, Hoshino Y, Kiyokawa H, Tanabe N, Sato A, Ogawa E, Muro S, Hirai T and Mishima M: p38 mitogen-activated protein kinase determines the susceptibility to cigarette smoke-induced emphysema in mice. BMC Pulm Med 14: 79, 2014.

15. Schnyder-Candrian S, Quesniaux VF, Di Padova F, Maillet I, Noulin N, Couillin I, Moser R, Erard F, Vargaftig BB, Ryffel B and Schnyder B: Dual effects of p38 MAPK on TNF-dependent bronchoconstriction and TNF-independent neutrophil recruitment in lipopolysaccharide-induced acute respiratory distress syndrome. J Immunol 175: 262-269, 2005

16. Tarchouna M, Ferjani A, Ben-Selma W and Boukadida J: Distribution of uropathogenic virulence genes in Escherichia coli isolated from patients with urinary tract infection. Int J Infect Dis 17: e450-e 453, 2013.

17. Blum-Oehler G, Dobrindt U, Janke B, Nagy G, Piechaczek K and Hacker J: Pathogenicity islands of uropathogenic E. coli and evolution of virulence. Adv Exp Med Biol 485: 25-32, 2000.

18. Derakhshandeh A, Firouzi R, Motamedifar M, Motamedi Boroojeni A, Bahadori M, Arabshahi S, Novinrooz A and Heidari S: Distribution of virulence genes and multiple drug-resistant patterns amongst different phylogenetic groups of uropathogenic Escherichia coli isolated from patients with urinary tract infection. Lett Appl Microbiol 60: 148-154, 2015.

19. Cirl C, Wieser A, Yadav M, Duerr S, Schubert S, Fischer H, Stappert D, Wantia N, Rodriguez N, Wagner H, et al: Subversion of Toll-like receptor signaling by a unique family of bacterial Toll/interleukin-1 receptor domain-containing proteins. Nat Med 14: 399-406, 2008

20. Snyder GA, Cirl C, Jiang J, Chen K, Waldhuber A, Smith P, Römmler F, Snyder N, Fresquez T, Dürr S, et al: Molecular mechanisms for the subversion of MyD88 signaling by TcpC from virulent uropathogenic Escherichia coli. Proc Natl Acad Sci USA 110: 6985-6990, 2013.
21. Yadav M, Zhang J, Fischer H, Huang W, Lutay N, Cirl C, Lum J, Miethke T and Svanborg C: Inhibition of TIR domain signaling by TcpC: MyD88-dependent and independent effects on Escherichia coli virulence. PLoS Pathog 6: el001120, 2010.

22. Waldhuber A, Puthia M, Wieser A, Cirl C, Dürr S Neumann-Pfeifer S, Albrecht S, Römmler F, Müller T, Zheng Y, et al: Uropathogenic Escherichia coli strain CFT073 disrupts NLRP3 inflammasome activation. J Clin Invest 126: 2425-2436, 2016.

23. Zhang C, Zhou JL, Fang J, Zhang DY, Wang BM, Chen RL and Pan JP: TcpC induces apoptosis of human vascular endothelial cells and its mechanisms. Zhejiang Da Xue Xue Bao Yi Xue Ban 42: 492-497, 2013 (In Chinese).

24. Zhang DY, Lin YQ, He F, Fang J, Zhang C, Wang BM and Pan JP: TcpC induces apoptosis of macrophages through promoting ROS production. Zhejiang Da Xue Xue Bao Yi Xue Ban 42: 486-491, 2013 (In Chinese).

25. Cox G: Glucocorticoid treatment inhibits apoptosis in human neutrophils. Separation of survival and activation outcomes. J Immunol 154: 4719-4725, 1995.

26. Ragnarsdóttir B and Svanborg C: Susceptibility to acute pyelonephritis or asymptomatic bacteriuria: Host-pathogen interaction in urinary tract infections. Pediatr Nephrol 27: 2017-2029, 2012.

27. Gupta K, Hooton TM, Naber KG, Wullt B, Colgan R, Miller LG, Moran GJ, Nicolle LE, Raz R, Schaeffer AJ, et al: International clinical practice guidelines for the treatment of acute uncomplicated cystitis and pyelonephritis in women: A 2010 update by the infectious diseases society of America and the European society for microbiology and infectious diseases. Clin Infect Dis 52: e103-e120, 2011.

28. Smith JA: Neutrophils, host defense, and inflammation: A double-edged sword. J Leukoc Biol 56: 672-686, 1994.

29. Segal AW: How neutrophils kill microbes. Annu Rev Immunol 23: 197-223, 2005

30. Svensson M, Irjala H, Svanborg C and Godaly G: Effects of epithelial and neutrophil CXCR2 on innate immunity and resistance to kidney infection. Kidney Int 74: 81-90, 2008.

31. Ng LG, Qin JS, Roediger B, Wang Y, Jain R, Cavanagh LL, Smith AL, Jones CA, de Veer M, Grimbaldeston MA, et al: Visualizing the neutrophil response to sterile tissue injury in mouse dermis reveals a three-phase cascade of events. J Invest Dermatol 131: 2058-2068, 2011.

32. Sadik CD, Kim ND and Luster AD: Neutrophils cascading their way to inflammation. Trends Immunol 32: 452-460, 2011

33. Shanley TP, Schmal H, Warner RL, Schmid E, Friedl HP and Ward PA: Requirement for $\mathrm{C}-\mathrm{X}-\mathrm{C}$ chemokines (macrophage inflammatory protein-2 and cytokine-induced neutrophil chemoattractant) in IgG immune complex-induced lung injury. J Immunol 158: 3439-3448, 1997.

34. Aratani Y, Miura N, Ohno N and Suzuki K: Role of neutrophil-derived reactive oxygen species in host defense and inflammation. Med Mycol J 53: 123-128, 2012 (In Japanese).

35. Armstrong DA, Major JA, Chudyk A and Hamilton TA: Neutrophil chemoattractant genes KC and MIP-2 are expressed in different cell populations at sites of surgical injury. J Leukoc Biol 75: 641-648, 2004

36. Hang L, Haraoka M, Agace WW, Leffler H, Burdick M, Strieter R and Svanborg C: Macrophage inflammatory protein-2 is required for neutrophil passage across the epithelial barrier of the infected urinary tract. J Immunol 162: 3037-3044, 1999.

37. Kurosaka K, Takahashi M and Kobayashi Y: Activation of extracellular signal-regulated kinase $1 / 2$ is involved in production of CXC-chemokine by macrophages during phagocytosis of late apoptotic cells. Biochem Biophys Res Commun 306: 1070-1074, 2003.

38. Kawaguchi M, Onuchic LF and Huang SK: Activation of extracellular signal-regulated kinase (ERK)1/2, but not $\mathrm{p} 38$ and c-Jun $\mathrm{N}$-terminal kinase, is involved in signaling of a novel cytokine, ML-1. J Biol Chem 277: 15229-15232, 2002.

39. Heit B, Liu L, Colarusso P, Puri KD and Kubes P: PI3K accelerates, but is not required for, neutrophil chemotaxis to fMLP. J Cell Sci 121: 205-214, 2008.

40. Zampetaki A, Mitsialis SA, Pfeilschifter J and Kourembanas S: Hypoxia induces macrophage inflammatory protein-2 (MIP-2) gene expression in murine macrophages via NF-kappaB: The prominent role of $\mathrm{p} 42 / \mathrm{p} 44$ and PI3 kinase pathways. FASEB J 18: 1090-1092, 2004. 